\title{
Production of carbonized micro-patterns by photolithography and pyrolysis $^{\text {is }}$
}

\author{
P.S. Ginestra ${ }^{\mathrm{a}, *}$, M. Madou ${ }^{\mathrm{b}}$, E. Ceretti ${ }^{\mathrm{a}}$ \\ ${ }^{\text {a }}$ Dept. of Mechanical and Industrial Engineering, University of Brescia, V. Branze 38, Brescia, IT, 25123, Italy \\ ${ }^{\mathrm{b}}$ Dept. of Mechanical and Aerospace Engineering, University of California S3231 Engineering Gateway Mail Code: 3975, Irvine, CA, 92697, USA
}

\section{A R T I C L E I N F O}

\section{Keywords:}

Photolithography

Carbonization

Pyrolysis

\begin{abstract}
A B S T R A C T
The preparation of carbon micro-patterns is reported in this paper. Different carbon micro-patterns were created using photolithography of the epoxy-based negative photoresist SU-8. Photoresist patterns were optimized in terms of resolution and aspect ratio and subsequently subjected to pyrolysis to obtain carbonized and conductive 3D structures. The latter step requires the optimization of the resist cross-linking time as well as the temperature and time of the resist post-bake. This step is crucial in order to avoid any severe modification of the geometry of the patterns produced during the actual pyrolysis. By observing optical and scanning electron microscope images, the morphology of the structures before and after pyrolysis was studied and the same patterns were also characterized by a laser probe profilometer. Finally, the thus obtained carbon patterns on Si wafers were used to carry out cell culture tests with Neural Stem Cells (NSC). The adhesion and the arrangement of the stem cells were analyzed to verify the ability of the patterned substrates to guide the orientation and, therefore, the differentiation of the cells.
\end{abstract}

\section{Introduction}

Patterned organic polymers are considered a promising material for many applications [1-3]. Polymer micro and nano-patterning techniques include molding, mechanical machining and lithography. Photolithography techniques offer a balance between the quality and the complexity of the final specified dimensions by patterning with light [4]. Typically, a photolithography mask is designed to enable the selective passage of UV light onto a photoresist layer, changing its chemical composition according to the desired final topography. The epoxy-based negative photoresist SU-8 has been used extensively to form large aspect ratio thick resist structures due to its low absorption in the UV spectrum [5]. If the UV absorption in a polymer is too high the patterning of thick coatings is rendered impossible as the light cannot penetrate deep enough even at high doses [6]. In the case of SU8 the UV light can penetrate very deep and this coupled with a high degree of cross-linking allows for high aspect ratio straight sidewalls with good structural definition and high quality [7]. Moreover SU-8 exhibits excellent chemical and thermal stability. However, the properties of the SU-8 are very sensitive to even minor variations of the processing parameters $[8,9]$. The cross-linking of the photoresist depends on the combination of the exposure time and energy and the post exposure baking conditions. Specifically, the reproduction of small features is enhanced by using a low exposure dose and a high post exposure bake [4]. In the production of carbon micro-electromechanical systems (CMEMS), pyrolysis follows the photolithography process to produce a carbon pattern from the polymer precursor. Carbonization takes place in a furnace with the photoresist subjected to a heat treatment in an inert atmosphere [10]. At temperatures above $900{ }^{\circ} \mathrm{C}$ the resulting carbon content of the residue is expected to exceed a mass fraction of $>90 \%$ in weight. TEM and X-ray analysis performed on the pyrolyzed photoresist reveal that in most cases the microstructure is similar to that of commercial glassy carbon with its high impermeability, high conductivity and excellent electrochemical characteristics [11]. By changing the deposition method of the precursor polymer (e.g. electrospinning instead of spin coating) the graphitic content of the resulting carbon can be modified which in turn changes the electrical and electrochemical properties of the material [12]. The SU-8 patterned structures shrink during carbonization [13] and the percentage of vertical shrinkage varies from $60 \%$ to $80 \%$ [10] and is found to be directly proportional to the pyrolysis temperature and inversely proportional to the height of the precursor layer [14]. Most of the SU-8 shrinkage occurs at low temperatures (i.e. $600^{\circ} \mathrm{C}$ ) due to the fact that the bulk of decomposition products escape at those lower

\footnotetext{
This paper was recommended by Associate Editor Maurizio Galetto.

* Corresponding author.

E-mail address: paola.ginestra@unibs.it (P.S. Ginestra).
} 
temperatures. Resist shrinkage in the $\mathrm{X}$-Y plane is substantially less than in the $\mathrm{Z}$ direction because the resist is anchored to a fixed substrate ( $\mathrm{Si}$ in our case) [15]. The SU-8 properties combined with the opportunities offered by the photolithography and the pyrolysis processes make this production system suitable for a wide range of applications like CMEMS $[16,17]$, micro optics, micro machining, analytical micro fluidic applications [18], electro analytical chemistry, electro synthetic chemistry, and energy conversion [19], biosensor, bio-analytical systems [20] and biomedical device applications [21].

The engineered scaffolds used in the biomedical industry are designed to promote cellular adhesion, proliferation and differentiation [22-24]. Such a substrate must have distinct properties to facilitate the interaction with a specific cellular phenotype [25]. Implanted structures must also have mechanical and morphological properties aimed at the success of the implant [26-28]. Other devices are used to guide a certain differentiation of stem cells by enabling cellular stimulation by their structure and material composition [29,30]. Such substrates can be used in in-vitro experiments as long as they allow the detachment of the cells after treatment. In neural tissue engineering, electrical stimuli together with a controlled topography (e.g., aligned nanofibers) have been identified as key parameters to promote nerve regeneration and neural stem cells differentiation; in particular, nerve guidance channels are indicated to induce a forced organization of the cells that can lead to a cytoskeletal modification according to the channels direction [31-33]. Photolithography has been used for the production of scaffolds and the manufacturing of biomaterials at small scales for tissue engineering applications [34-36]. On the other hand, the pyrolysis technique has been considered less frequently and specifically for neural tissue engineering $[37,38]$. In this paper, the production of different carbonized SU-8 patterns produced by photolithography is reported to highlight the possibility of using the combination of both the selected techniques for the fabrication of patterned and carbonized substrates. The patterns geometry was designed considering the typical configurations used in micro fluidic and biomedical applications [39-41]. The morphology of the patterns was evaluated by optical and electron microscope images. A laser probe profilometer has been used to investigate the shrinkage at different aspect ratios of the designed structures. Lastly, neural stem cells have been seeded on the patterned substrates to investigate the effect of the configurations of the patterns on the cells adhesion and orientation.

\section{Production of the carbon patterns}

Silicon wafers were used as the substrate for the SU-8 negative photoresist photolithography process. Different geometric configurations were designed for the selective cross-linking of the polymer and the production of patterned wafers. Following this process, the wafers were subjected to pyrolysis to obtain patterned glassy-carbon structures.

\subsection{Pattern designs}

Two main SU-8 patterns were designed as shown in Fig. 1. Configuration $\mathrm{A}$ and $\mathrm{B}$ are characterized by lines having two different widths $\left(\mathrm{w}_{0}\right)$ equal to $25 \mu \mathrm{m}$ and $35 \mu \mathrm{m}$, and two different pitches $\left(\mathrm{d}_{0}\right)$ equal to $25 \mu \mathrm{m}$ and $35 \mu \mathrm{m}$ respectively (Fig. 1 ).

\subsection{Photolithography and pyrolysis}

The patterns $\mathrm{A}$ and $\mathrm{B}$ were printed in an optimized photolithography process, using SU-8 3050 on silicon wafers (Si wafers) and on silicon wafers with a silicon dioxide layer $\left(\mathrm{SiO}_{2}\right.$ wafers). The newer SU-8 3050 (Microchem $^{\odot}$ ) resist is listed in the company material as having improved adhesion to the Si wafer, reduced coating stress and an enhanced resolution for high aspect ratio structures compared to previous SU-8 resist types [42]. The Si substrates were cleaned and

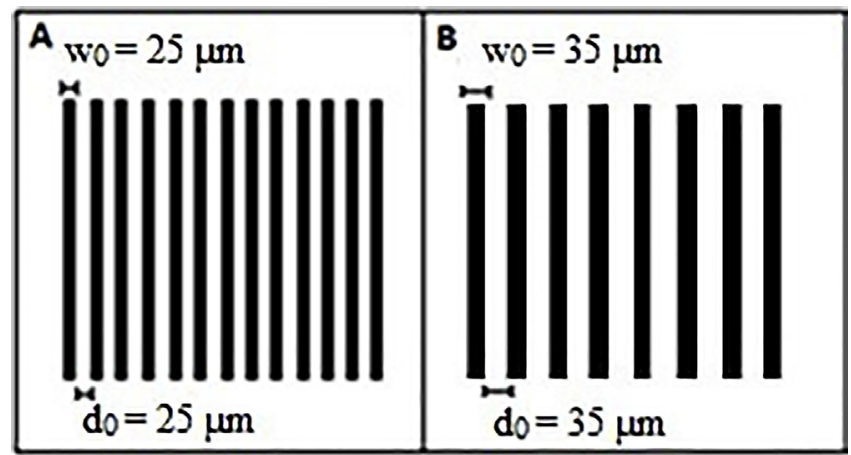

Fig. 1. Pattern configurations A and B.

dried prior spin-coating of the photoresist. A first thin film $(2 \mu \mathrm{m})$ of SU2002 was spin coated and fully exposed on the $\mathrm{SiO}_{2}$ wafers to enhance adhesion between the subsequent SU- 8 layer and the substrate, and to reduce the tensile stress on the structures. SU-8 3050 was spin-coated at $3000 \mathrm{rpm}$ to a desired film thickness of $50 \mu \mathrm{m}$ on both Si wafers and $\mathrm{SiO}_{2}$ wafers. The final height of the structures depends on the dispensed volume of the polymer solution, viscosity of the solution and the spincoating process. The Microchem Corporation provides information about parameters such as viscosity, spin speed, recommended times and temperature for softbake, the post-exposure bake steps and the exposure time in the datasheets of the specific SU-8 resist. The most important parameters of the photolithography process are reported in Table 1. After the spin-coating process, the UV exposure was performed in hard contact mode to minimize air gaps throughout the exposure area and an exposure time (ET) less than the recommended one in the processing datasheet ( $22 \mathrm{~s}$ vs $25 \mathrm{~s}$ ) were used to minimize the chance of starting a cross-linking reaction in the gaps between the resist lines. The exposure time could not be reduced too drastically in order to prevent under-exposure with line walls no longer straight and a shape that is no longer uniform along the height of the structures. The soft bake (SB) and the post-exposure bake (PEB) were carried out using a ramp of $2{ }^{\circ} \mathrm{C} / \mathrm{min}$ to reach the final temperatures and the wafers were allowed to cool down to room temperature after both baking processes to ensure complete cross-linking and to avoid the collapse of the gaps between the lines due to stiction forces [43]. A commercially available SU-8 developer was employed for dissolving the uncross-linked SU-8 after the photolithography process.

The pyrolysis process of the SU- 8 patterns was carried out in two steps. First, the patterns were pre-conditioned at $270{ }^{\circ} \mathrm{C}$ for three hours to thermally stabilize them. Next, the wafers were placed in a furnace for the pyrolysis at $950{ }^{\circ} \mathrm{C}$ with a $10^{\circ} \mathrm{C} / \mathrm{min}$ ramp rate in a Nitrogen atmosphere [44]. The two steps heating process, with its slow heating rate, helps releasing the tensile stress due to the cross-linking of the polymer that usually causes stress in the carbon features near the interface [21]. The entire fabrication procedure is explained step by step in Fig. 2a.

Most of the shrinkage during pyrolysis in SU-8 takes place at low temperatures suggesting that most of the gas evolution is over by a low temperature and there is not much of pyrolysis reactions at higher temperatures [45]. The shrinkage that normally occurs during pyrolysis

Table 1

Designed photolithography process for a $50 \mu \mathrm{m}$ SU-8 3050 layer.

\begin{tabular}{lll}
\hline Parameter & Description & Set value \\
\hline Spin speed & Spin coating speed & $3000 \mathrm{rpm}$ \\
SB & Soft baking & $15 \mathrm{~min}$ at $95^{\circ} \mathrm{C}$ \\
ET & Exposure time & $22 \mathrm{~s}$ \\
PEB & Post-exposure baking & $1 \mathrm{~min}$ at $65^{\circ} \mathrm{C}$ and $5 \mathrm{~min}$ at $95^{\circ} \mathrm{C}$ \\
DT & Development time & 15 min \\
\hline
\end{tabular}


(a)

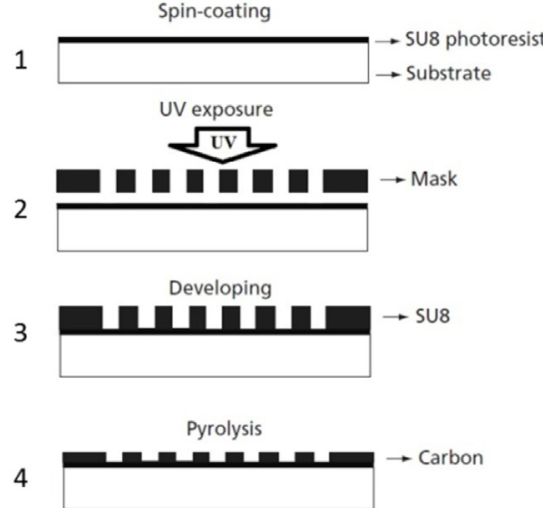

(b)

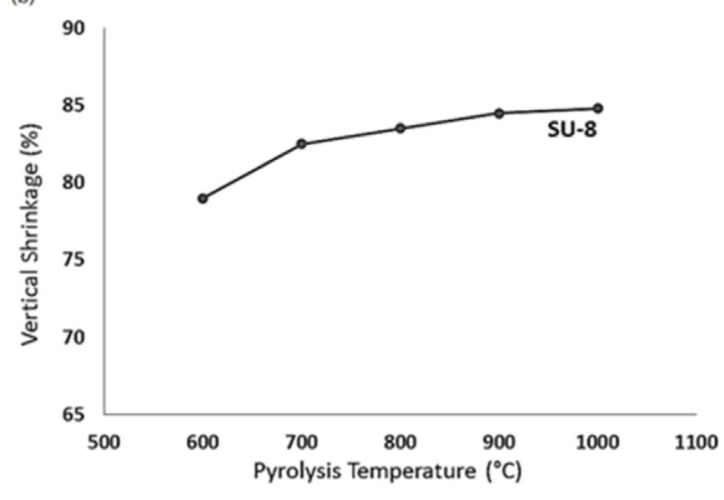

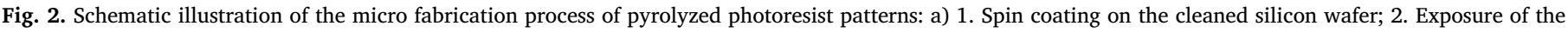

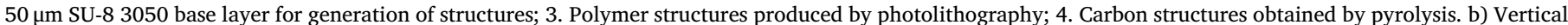
shrinkage in SU-8 upon pyrolysis in 5\% H2 and 95\% N2 at various temperatures [38].

is reported in Fig. 2b. This could be explained on the basis of the thermogravimetric analysis typical of the negative photoresist where a copious gas evolution is observed [45].

Since during the pyrolysis of SU-8 most of the copious gas evolution occurs in a relatively short temperature range, the adhesion of the film to the substrate is compromised. Therefore, when thick SU-8 films on silicon are pyrolyzed, the resulting carbon film peels off.

\section{Pattern characterization}

The patterns obtained on the Si wafers were characterized before and after pyrolysis with optical and electron microscopy. All patterns were also examined by a laser probe profilometer.

\subsection{Analysis of the morphology after photolithography}

Fig. 3 displays the SEM images of the patterned (configuration A and $\mathrm{B}) \mathrm{SiO}_{2}$ coated $\mathrm{Si}$ wafers after the photolithography steps.

The cross-section images reveal the shape of the channels between the lines after photolithography. Both configurations show that the lines exhibit a slight $\mathrm{V}$ profile due possibly to under-exposure of the structure [46]. More straight sidewalls can be achieved with the proper optimization of the exposure time (ET) and the post-exposure baking time. The above images were properly processed with ImageJ software $[47,48]$ to extract the pattern thicknesses for both configurations. The thickness after the photolithography was congruent with the nominal thickness $(50 \mu \mathrm{m})$ of the spin coated SU-8 and in particular resulted in $50.8 \pm 1.54 \mu \mathrm{m}$ for configuration A and $48.7 \pm 0.76 \mu \mathrm{m}$ for configuration $\mathrm{B}$ based on three repetitions of the same measurements.

The bare Si patterned wafers were investigated only via optical microscopy. Fig. 4 shows the images of the configuration A and B. There is no reason to presume that both the sidewall and the thickness of the channels are different in this case compared to the oxide coated wafer case and for this reason the cross-section of these samples was not observed.

Table 2 reports the data of the dimensional analysis performed on the SEM and optical microscope images. The data reveal the difference between the nominal $\left(\mathrm{w}_{0}, \mathrm{~d}_{0}\right)$ and the actual obtained widths and pitches $\left(w_{p h}, d_{p h}\right)$. The difference is mostly due to the cross-linking of the photoresist.

The exposure and the post-exposure processes that enhanced the adhesion of the resist to the substrate resulted in an optimal replication of the nominal structures on the substrates by photolithography of the SU-8. The percentage of variation in the patterned geometry is typically within a range of $\pm 1 \mu \mathrm{m}$. The higher $(\geq 3 \mu \mathrm{m})$ geometrical variation displayed by the patterns on the Si wafer with the B configuration might be caused by a less adequate contact between the mask and the substrate during the exposure.

\subsection{Analysis of the morphology after pyrolysis}

Figs. 5 and 6 show the optical microscope images of the patterns on the $\mathrm{SiO}_{2}$ and the $\mathrm{Si}$ wafers after the pyrolysis of configurations A and $\mathrm{B}$.

The optical microscope images were processed with the same software ImageJ to analyze the pattern dimensions. Table 3 reports the data of the dimensional analysis performed on the images that results in more significant dimensional differences with respect to the configurations analyzed above after the photolithography process.

During pyrolysis, the uniform shrinkage of the photoresist network often results in a carbon network with increased openings [21]. The differences between the widths and pitches $\left(\mathrm{w}_{\mathrm{ph}}, \mathrm{d}_{\mathrm{ph}}\right)$ obtained after photolithography and the ones obtained after pyrolysis $\left(w_{p y}, d_{p y}\right)$ are resulting from the shrinkage occurring during pyrolysis and are more evident for the patterns on the $\mathrm{SiO}_{2}$ wafers than on the $\mathrm{Si}$ wafers. In the author's opinion, the shrinkage effect that normally takes place during the heat treatment might be higher in presence of the dioxide film on the wafers. However, with respect to a typical percentage of shrinkage (Fig. 2) [45,49] occurring during pyrolysis, the changes in lateral dimensions were acceptable for the Si wafers (3-12\%) while the changes of the patterns on the $\mathrm{SiO}_{2}$ wafers were considerable larger (40\%).
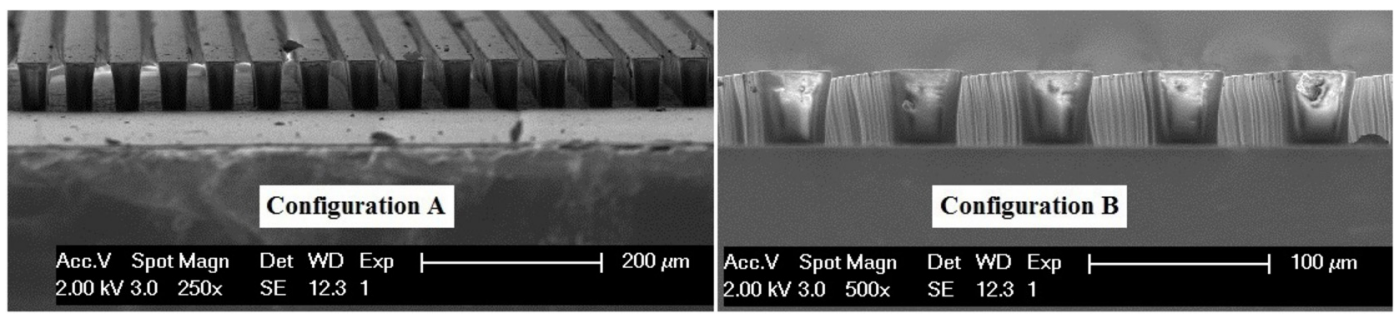

Fig. 3. SEM images of configuration $\mathrm{A}$ and $\mathrm{B}$ on the $\mathrm{SiO}_{2}$ wafers after photolithography. 

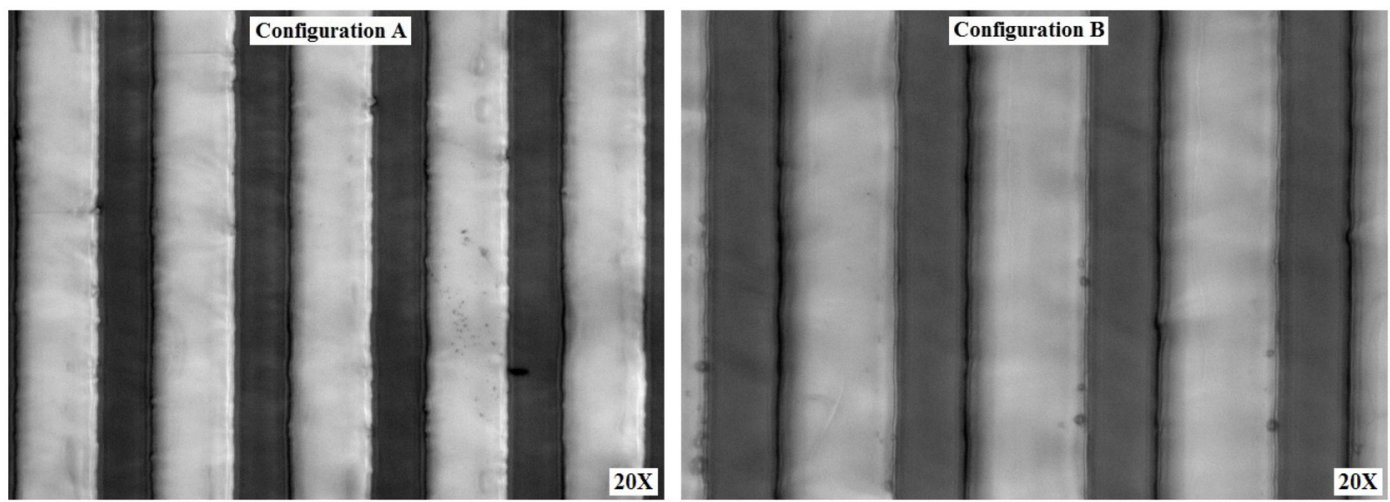

Fig. 4. Optical microscope images $20 \mathrm{X}$ of configuration A and B on the Si wafers after photolithography.

Table 2

Nominal pattern configurations and resulting dimensions of the pattern after photolithography. SEM and optical microscope measurements.

\begin{tabular}{llllll}
\hline $\begin{array}{l}\text { Nominal } \\
\text { feature } \mathrm{w}_{0} \\
(\mu \mathrm{m})\end{array}$ & $\begin{array}{l}\text { Wafer feature } \mathrm{w}_{\mathrm{ph}} \\
(\mu \mathrm{m})\end{array}$ & $\begin{array}{l}\text { Nominal } \\
\text { feature } \mathrm{d}_{0} \\
(\mu \mathrm{m})\end{array}$ & Wafer feature $\mathrm{d}_{\mathrm{ph}}(\mu \mathrm{m})$ \\
\hline $25(\mathrm{~A})$ & $\mathrm{SiO}_{2}$ & $25.1 \pm 1.4$ & $25(\mathrm{~A})$ & $\mathrm{SiO}_{2}$ & $24.2 \pm 1.1$ \\
$35(\mathrm{~B})$ & $\mathrm{SiO}_{2}$ & $33.9 \pm 1.2$ & $35(\mathrm{~B})$ & $\mathrm{SiO}_{2}$ & $34.6 \pm 1.2$ \\
$25(\mathrm{~A})$ & $\mathrm{Si}$ & $25.3 \pm 1.2$ & $25(\mathrm{~A})$ & $\mathrm{Si}$ & $25.6 \pm 1.1$ \\
$35(\mathrm{~B})$ & $\mathrm{Si}$ & $38.2 \pm 0.6$ & $35(\mathrm{~B})$ & $\mathrm{Si}$ & $31.1 \pm 1.1$ \\
\hline
\end{tabular}

\subsection{Laser probe profilometer after pyrolysis}

The Mitaka ${ }^{\odot}$ PF-60 [50] laser profilometer was used to investigate the cross sectional profile of the channels after pyrolysis. The nonpyrolyzed patterns were not clearly resolved by the profilometer and the resulting profile was not reliable. A length of $4 \mathrm{~mm}$ on the surface of the carbon patterned wafers with and without the dioxide film was analyzed (Fig. 8). The profile of configurations A and B was evaluated for the measurements of the width of the channels and the different pitches on the $\mathrm{SiO}_{2}$ wafers (Fig. 7) and the Si wafers (Fig. 8):

As shown in the zoomed detail of Fig. 7, the interpolation of the profile carried out by means of the Mitaka Map [51] software after the acquisition is probably causing an artifact that has to be neglected in the measuring process of the width and, therefore, the pitch value. The dimensional differences between the measurements taken by image processing and profile acquisition have been attributed to the different methods employed to collect the data. As explained above, the shrinkage during the pyrolysis is strongly affecting the geometry of the channels on the $\mathrm{SiO}_{2}$ wafers (30-40\% of variation). In general, this effect causes a reduction of the nominal width of high aspect ratio structures as shown in Table 4. The effect of the shrinkage (Fig. 2) is reflected also on the value of the resulting pitch $\mathrm{d}_{\mathrm{py}}$ in all configurations.

Another important effect of the shrinkage is the final thickness of the structures that is different from the thickness of the initial SU-8 layer. As reported in Table 5, the thickness of the pattern is modified by a vertical shrinkage that especially affects the height of the channels of configuration A on the Si wafers. In particular, the reduction of the thickness is under the typical shrinkage percentages reported for this type of process $(86,57 \%$ in Nitrogen curing atmosphere [45,49,52]) in case of the configuration A on the $\mathrm{SiO}_{2}$ wafers (33\%). This relatively promising result can however directly depend on the high lateral shrinkage reported in the previous section. Moreover, the vertical shrinkage of the Si wafers patterned with configuration B is moderate (46\%). Nevertheless, the shrinkage percentages reported for the other substrates are close to the typical values reported in the literature [45].

It has to be remembered that the thickness of thick layers of SU-8 can vary significantly [53] even after the spin-coating process with a variation of about $\pm 30 \mu \mathrm{m}$ usually between the center and the edge of the wafer [20]. The shrinkage of the carbon patterns is also dependent on the overall height of the structure [21]. Moreover, it has been reported that Nitrogen atmosphere produces the highest shrinkage due to oxygen traces in the curing atmosphere.

\section{Biological tests}

169. The Si wafers patterned with configuration B were subjected to cell culture tests with Neural Stem Cells (NSC). The adhesion and the arrangement of the stem cells have been analyzed to verify the ability of the patterned substrates to guide the orientation and, therefore, the differentiation of the cells. In particular, the cellular morphology has been studied by immunofluorescent microscope images. The differences between the unpyrolyzed and pyrolyzed patterned substrates on the
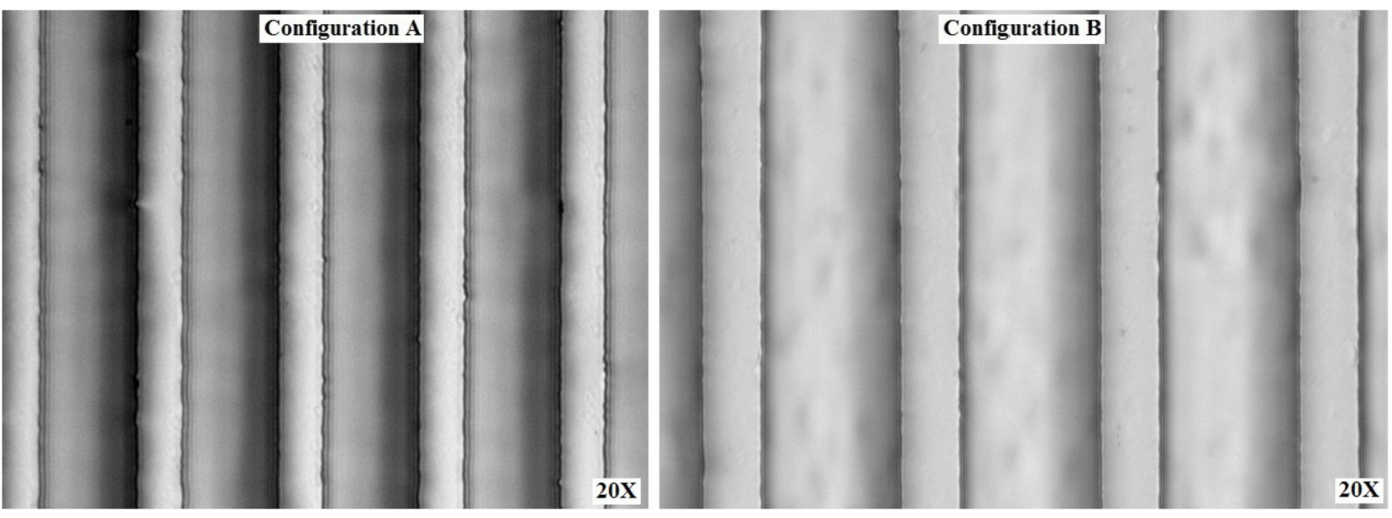

Fig. 5. Optical microscope images $20 \mathrm{X}$ of configuration $\mathrm{A}$ and $\mathrm{B}$ on the $\mathrm{SiO}_{2}$ wafers after pyrolysis. 

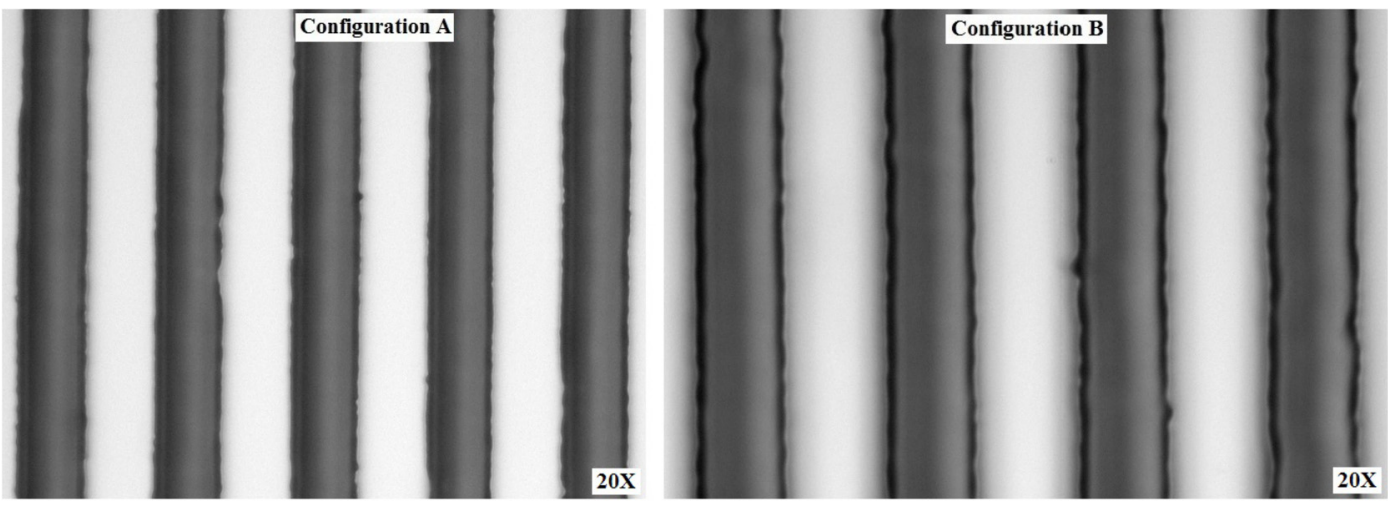

Fig. 6. Optical microscope images 20X of configuration A and B on the Si wafers after pyrolysis.

Table 3

Pattern configurations by photolithography and resulting dimensions of the patterns after pyrolysis. Optical microscope measurements.

\begin{tabular}{|c|c|c|c|c|c|c|c|}
\hline \multicolumn{2}{|c|}{ Wafer feature $\mathrm{w}_{\mathrm{ph}}(\mu \mathrm{m})$} & \multicolumn{2}{|c|}{ Wafer feature $\mathrm{w}_{\mathrm{py}}(\mu \mathrm{m})$} & \multicolumn{2}{|c|}{ Wafer feature $d_{p h}(\mu \mathrm{m})$} & \multicolumn{2}{|c|}{ Wafer feature $d_{p y}(\mu \mathrm{m})$} \\
\hline $\mathrm{SiO} 2(\mathrm{~A})$ & $25.1 \pm 1.4$ & $\mathrm{SiO} 2(\mathrm{~A})$ & $15.7 \pm 0.5$ & $\mathrm{SiO} 2(\mathrm{~A})$ & $24.2 \pm 1.1$ & $\mathrm{SiO} 2(\mathrm{~A})$ & $34.9 \pm 1.2$ \\
\hline $\mathrm{SiO} 2(\mathrm{~B})$ & $33.9 \pm 1.2$ & $\mathrm{SiO} 2(\mathrm{~B})$ & $21.6 \pm 0.6$ & $\mathrm{SiO} 2$ (B) & $34.6 \pm 1.2$ & $\mathrm{SiO} 2(\mathrm{~B})$ & $50.7 \pm 1.5$ \\
\hline $\mathrm{Si}$ (A) & $25.3 \pm 1.2$ & $\mathrm{Si}(\mathrm{A})$ & $24.6 \pm 0.7$ & $\mathrm{Si}(\mathrm{A})$ & $25.6 \pm 1.1$ & $\mathrm{Si}(\mathrm{A})$ & $26.3 \pm 0.5$ \\
\hline
\end{tabular}
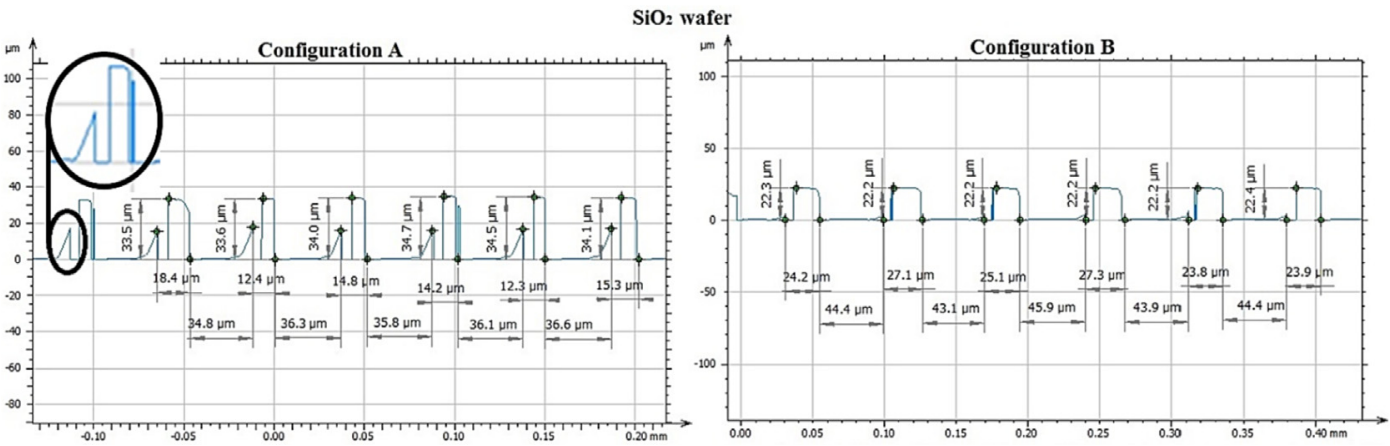

Fig. 7. Profile of the configuration A (on the right) and $\mathrm{B}$ (on the left) on the $\mathrm{SiO}_{2}$ wafers. In the circled detail of configuration A: the detail of the artifact produced during the interpolation of the profile.

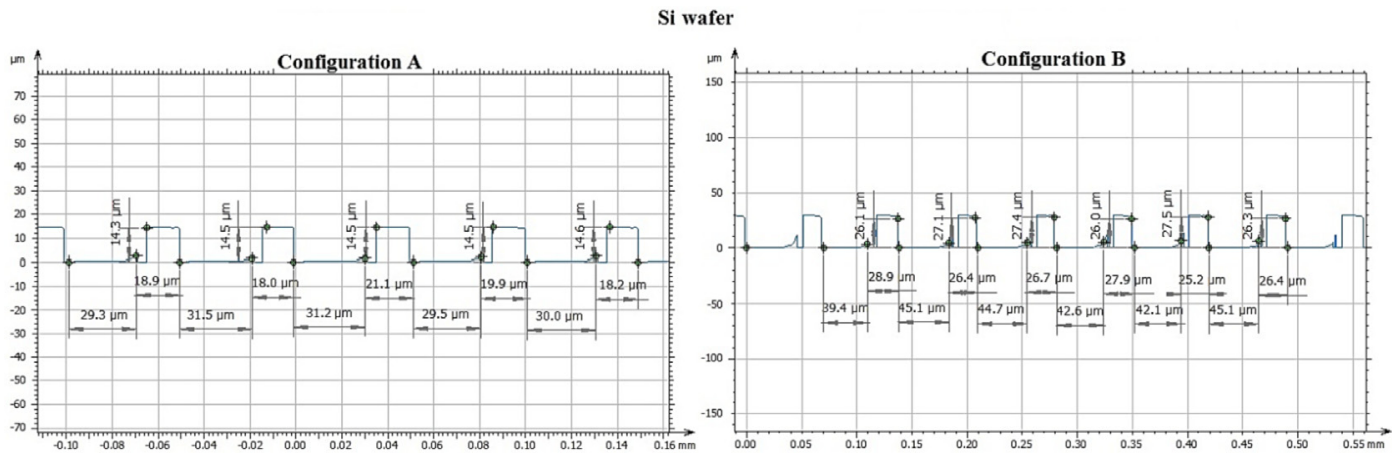

Fig. 8. Profile of the configuration A (on the right) and B (on the left) on the Si wafers.

Table 4

Pattern configurations by photolithography and resulting dimensions of the patterns after pyrolysis. Profilometer measurements.

\begin{tabular}{|c|c|c|c|c|c|c|c|}
\hline \multicolumn{2}{|c|}{ Wafer feature $\mathrm{w}_{\mathrm{ph}}(\mu \mathrm{m})$} & \multicolumn{2}{|c|}{ Wafer feature $w_{\text {py }}(\mu \mathrm{m})$} & \multicolumn{2}{|c|}{ Wafer feature $d_{p h}(\mu m)$} & \multicolumn{2}{|c|}{ Wafer feature $d_{p y}(\mu m)$} \\
\hline $\mathrm{SiO} 2(\mathrm{~A})$ & $25.1 \pm 1.4$ & $\mathrm{SiO} 2(\mathrm{~A})$ & $14.4 \pm 1.2$ & $\mathrm{SiO} 2(\mathrm{~A})$ & $24.2 \pm 1.1$ & $\mathrm{SiO} 2(\mathrm{~A})$ & $35.9 \pm 0.6$ \\
\hline $\mathrm{SiO} 2(\mathrm{~B})$ & $33.9 \pm 1.2$ & $\mathrm{SiO} 2(\mathrm{~B})$ & $25.5 \pm 1.5$ & $\mathrm{SiO} 2(\mathrm{~B})$ & $34.6 \pm 1.2$ & $\mathrm{SiO} 2(\mathrm{~B})$ & $44.3 \pm 1$ \\
\hline Si (A) & $25.3 \pm 1.2$ & Si (A) & $19.2 \pm 1.2$ & $\mathrm{Si}(\mathrm{A})$ & $25.6 \pm 1.1$ & $\mathrm{Si}(\mathrm{A})$ & $30.3 \pm 0.9$ \\
\hline Si (B) & $38.2 \pm 0.6$ & Si (B) & $27.3 \pm 1.1$ & $\mathrm{Si}(\mathrm{B})$ & $31.1 \pm 1.1$ & $\mathrm{Si}(\mathrm{B})$ & $43.9 \pm 1.4$ \\
\hline
\end{tabular}


Table 5

Nominal thickness of the SU-8 film and resulting dimensions of the thickness after pyrolysis. Profilometer measurements.

\begin{tabular}{lllll}
\hline Nominal thickness $(\mu \mathrm{m})$ & \multicolumn{2}{l}{ Wafer feature thickness $(\mu \mathrm{m})$} & \multicolumn{2}{l}{ Shrinkage (\%) } \\
\hline $50($ A) & $\mathrm{SiO} 2(\mathrm{~A})$ & $33.3 \pm 0.7$ & $\mathrm{SiO} 2(\mathrm{~A})$ & 33 \\
50 (B) & $\mathrm{SiO} 2(\mathrm{~B})$ & $22.2 \pm 0.05$ & $\mathrm{SiO} 2(\mathrm{~B})$ & 55 \\
50 (A) & $\mathrm{Si} \mathrm{(A)}$ & $14.5 \pm 0.1$ & $\mathrm{Si}(\mathrm{A})$ & 71 \\
50 (B) & $\mathrm{Si} \mathrm{(B)}$ & $26.9 \pm 0.6$ & $\mathrm{Si} \mathrm{(B)}$ & 46 \\
\hline
\end{tabular}

cellular adhesion and orientation have also been highlighted.

\subsection{Cell culture}

170. Before cell seeding, the substrates were sterilized with an EtOH $70 \%$ solution for $30 \mathrm{~min}$ and UV light for $20 \mathrm{~min}$ and then washed with phosphate buffered saline (PBS). The substrates were then coated with Corning $^{\mathrm{TM}}$ Matrigel $^{\mathrm{TM}} \mathrm{hESC}-\mathrm{Qualified}$ Matrix for $1 \mathrm{~h}$. Human iPSC-derived neural stem cells were seeded on a $1 \mathrm{~cm}^{2}$ area of the patterned substrates. Cultures were dissociated with StemPro ${ }^{\circ}$ Accutase ${ }^{\oplus}$ and filtered to remove spheroids and floating sphere colonies, re-suspended as single cells, and seeded at a cellular density of 20,000 cells $/ \mathrm{cm}^{2}$. Concentrated cell suspension was deposited onto each substrate and incubated for $30 \mathrm{~min}$ before filling the culture dish with a proper volume of culture medium. The cells were cultured using the Neural Expansion Medium. All cell culture reagents were purchased from Thermo Fisher Scientific ${ }^{\odot}$. Cells were maintained at $37^{\circ} \mathrm{C}$ in a saturated humidity atmosphere containing 95\% air and 5\% CO2.

\subsection{Immunofluorescence (IF) staining}

The samples were observed with an inverted fluorescent microscope and the organization of the cytoskeletal protein Nestin was evaluated to analyze the arrangement of the cells [54,55]. After 5 days the cells were treated using the Fix\&Perm Sample Kit ${ }^{\circledR}$ (Nordic MUbio ${ }^{\circledR}$ ) for $30 \mathrm{~min}$ (15 min fixation and 15 min permeabilization). For staining, the cells were incubated firstly with the blocking solution (iBind ${ }^{\mathrm{TM}} 5 \mathrm{X}$ Buffer) and then with the anti-Nestin antibody $\left(\mathrm{Abcam}^{\odot}{ }^{\circ}\right.$ ) for $3 \mathrm{~h}$ at room temperature. After washing with D-PBS, cells were stained with Alexa Fluor 568 (ThermoFisher $^{\odot}$ ) for $1 \mathrm{~h}$ in the dark. Cell nuclei were then counterstained with Hoechst 33342 in PBS for 5 min to highlight the cellular nuclei of the living neurons. The samples were mounted onto glass slides before imaging. The images of the nuclei (blue) and the Nestin (red) in our samples show that NSCs tend to spread in all directions in the absence of a pattern (Fig. 9).
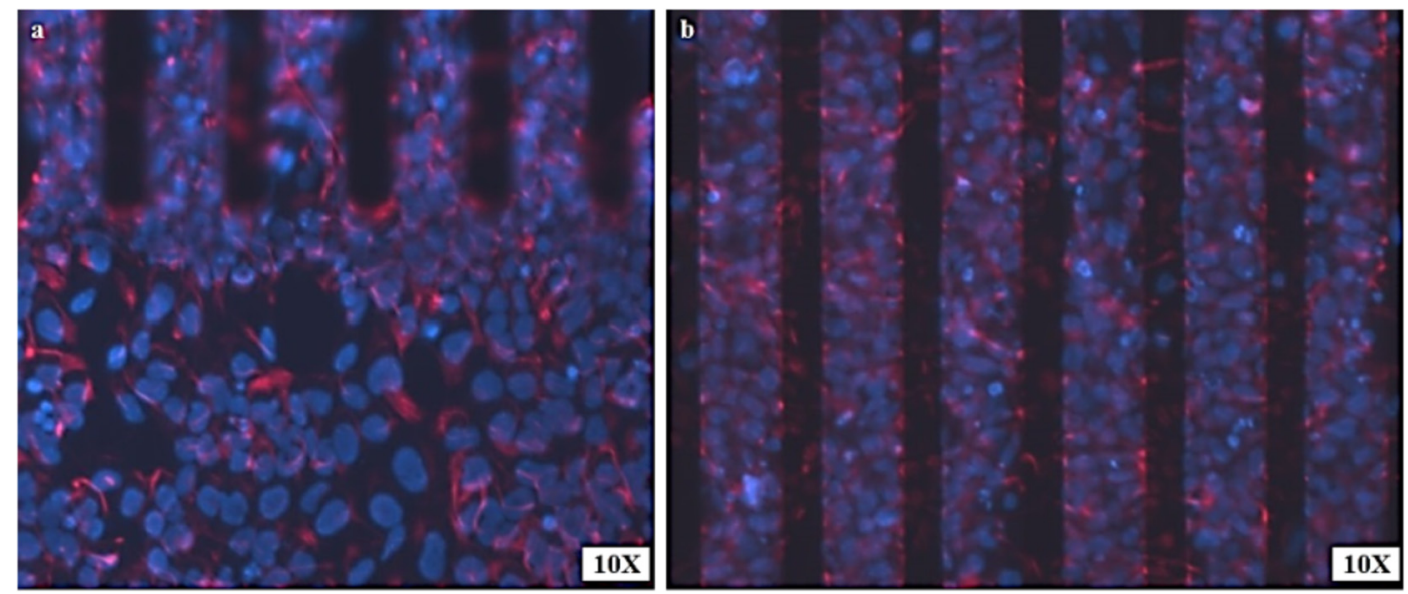

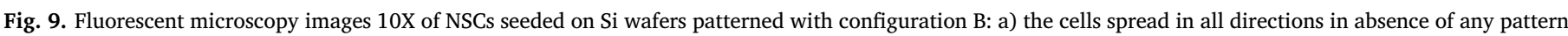

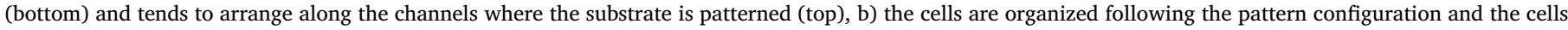
are communicating through the channels walls as highlighted by the protrusions of the cytoskeletal protein Nestin.
The pattern can stimulate the cells to regulate their cytoskeletal orientation according to the design. In particular, neural stem cells seem to modify their original morphology (spherical) as a consequence of their arrangement along the channels (Fig. 9b).

\section{Discussion and conclusions}

In this paper, SU-8 3050 patterns are produced by photolithography on silicon wafers with $\left(\mathrm{SiO}_{2}\right)$ and without $(\mathrm{Si})$ the dioxide film. The wafers have been also subjected to pyrolysis after the photolithography process to obtain glassy-carbon patterns on the substrates. Two high aspect-ratio configurations have been designed in order to be applied during the two production processes. Narrower channels with respect to the configuration B characterize the configuration A. Channels with different widths and pitches characterize the patterns. The morphology of the patterns on the wafers has been evaluated. The dimensional differences between the nominal pattern geometry and the structures produced by photolithography are caused by the cross-linking of the polymer due to the exposure time and the post-baking time that are core parameters affecting the production of high aspect-ratio structures. The nominal widths and the pitches of the channels were well represented on the surface of all the wafers after the development of SU-8. On the other hand, the measurements of the geometry performed with both optical microscope images and profile acquisitions after pyrolysis highlighted that the dimensional differences were considerable. In particular, the widths and the pitches of the pyrolyzed channels on the $\mathrm{SiO}_{2}$ wafers were varied by the heat treatment in a percentage around $40 \%$ while the carbon structures on the Si wafers were changed only in a percentage less than $12 \%$. According to the literature $[45,49]$, the curing atmosphere can affect the shrinkage during pyrolysis. In particular, in a Nitrogen atmosphere used here, the reported values are around the $86 \%$ at $900^{\circ} \mathrm{C}$. Here, the vertical shrinkage (thickness reduction) was $30 \%$ and $70 \%$ for the configuration A patterned on the $\mathrm{SiO}_{2}$ and the $\mathrm{Si}$ wafers respectively. Although it seems a promising outcome for the $\mathrm{SiO}_{2}$ the high lateral shrinkage reported for these samples could have affected the results. On the other hand, the shrinkage percentage for the configuration B was $65 \%$ and $46 \%$ on the $\mathrm{SiO}_{2}$ and the $\mathrm{Si}$ wafers respectively. In the author's experience, the shrinkage on the $\mathrm{SiO}_{2}$ wafers is higher than that of the $\mathrm{Si}$ wafers due to the presence of the dioxide film that can affect the adhesion of the structures on the wafers during the pyrolysis. Moreover, from these results, it seems that the narrower configuration can lead to a higher vertical shrinkage on the Si wafers. The influence of the patterns on cellular attachment and orientation was also evaluated. Neural stem cells were seeded on the wafers after pyrolysis. The results of the cell 
culture tests on the substrates confirm the strong influence of the pattern on cell orientations. According to the achieved results, the future researches will be focused on a more complete study of the quality of the patterns considering different process parameters. Furthermore, a statistical study of the orientation of the cells will be reported to evaluate the differences between the patterns configuration on the cellular arrangement with a quantitative description of what already evident in the fluorescent microscope images.

\section{Funding}

This research did not receive any specific grant from funding agencies in the public, commercial, or not-for-profit sectors.

\section{Acknowledgements}

The authors would like to acknowledge the support and the assistance of Dr. Arnoldo Salazar and Dr. Sunny Holmberg of University of California, Irvine.

\section{References}

[1] Shiny N, Kathiresan M, Mukundan T. Patterned water dispersible conducting polymer electrode in organic thin film transistor through a parylene lift-off process. Synth Met 2017;234:29-37.

[2] Hao F, Dajun Y, Rui G, Su Z, Ray PS, et al. Fabrication of patterned polymer nanowire arrays. ACS Nano 2011;5(2):1476-82.

[3] Park SH, Kang YJ, Majd SA. Review of patterned organic bioelectronic materials and their biomedical applications. Adv Mater 2015;27:7583-619.

[4] Martinez- Duarte R. SU-8 photolithography as a toolbox for carbon MEMS Micromachines 2014;5:766-82.

[5] Shaw JM, Gelorme JD, LaBianca NC, Conley WE, Holmes SJ. IBM JRes Dev 1997; 41:81.

[6] Lee KY, LaBianca N, Rishton SA, Zolgharnain S, Gelorme JD, Shaw J, et al, Micromachining applications of a high resolution ultrathick photoresist. J Vac Sci Technol B 1995;13:3012-6.

[7] Feng R, Farris RJ. Influence of processing conditions on the thermal and mechanical properties of SU8 negative photoresist coatings. J Micromech Microeng 2003;13:80-8.

[8] Lorenz H, Despont M, Vettiger P, Renaud P. Fabrication of photoplastic high-aspect ratio microparts and micromolds using SU-8 UV resist. Microsyst Technol 1998;4:143-6.

[9] Wang C, Jia G, Taherabadi LH, Madou MJ. A novel method for the fabrication of high-aspect ratio C-MEMS structures. J Microelectromech Syst 2005;14(2):348-58.

[10] Pesin LA. Structure and properties of glass-like carbon. J Mater Sci 2002;37:1-28.

[11] Mardegan A, Kamath R, Sharma S, Scopece P, Ugo P, Madou M. Optimization of carbon electrodes derived from epoxy-based photoresist. J Electrochem Soc 2013;160:132-7.

[12] Park B, Taherabadi L, Wang C, Zoval J, Madou MJ. Electrical properties and shrinkage of carbonized photoresist films and the implications for carbon microelectromechanical systems devices in conductive media. J Electrochem Soc 2005; 152:136-43.

[13] Genis TT, Zaouk R, Park YG, Madou MJ. Fabrication and characterization of threedimensional carbon electrodes for lithium-ion batteries. J Power Sources 2008;183:730-40.

[14] Martinez-Duarte R, Madou MJ. SU-8 photolithography and its impact on microfluidics. In: Mitra S, Chakraborty S, editors. Microfluidics and nanofluidics handbook: fabrication, implementation and applications. Boca Raton, FL, USA: CRC Press; 2009. p. 231-68.

[15] Martinez-Duarte R, Renaud P, Madou MJ. A novel approach to dielectrophoresis using carbon electrodes. Electrophoresis 2001;32:2385-92.

[16] Sharma S, Sharma A, Cho YK, Madou M. Increased graphitization in electrospun single suspended carbon nanowires integrated with carbon MEMS and carbonNEMS platforms. ACS Appl Mater Interfaces 2012;4(1):34-9.

[17] Sharma S, Madou MJ. Micro and nano patterning of carbon electrodes for bioMEMS. Bioinspired, Biomimetic Nanobiomaterials 2012;1:252-65.

[18] Liu G, Tian Y, Kann Y. Microsyst Technol 2005;11:343-6.

[19] McCreery RL. Chap. 10 Kissinger PT, Heineman WR, editors. Laboratory techniques in electroanalytical chemistry. second ed.New York: Marcel Dekker; 1996.

[20] Garcia C, Schomacker A, Klarholz I, Harms C, Lang W. Fabrication of microfluidic devices using SU-8 for detection and analysis viruses. Proceedings of AMA conference, I-B3.3. 2009.

[21] Wang C, Madou MJ. From MEMS to NEMS with carbon. Biosens Bioelectron 2005;20. 2181-7.

[22] Ginestra P, Ceretti E, Fiorentino A. Electrospinning of poly-caprolactone for scaffold manufacturing: experimental investigation on the process parameters influence. Proc CIRP 2016;49:8-13.

[23] Ginestra PS, Ghazinejad M, Madou M, Ceretti E. Fabrication and characterization of polycaprolactone-graphene powder electrospun nanofibers. Proc. SPIE 9932, carbon nanotubes, graphene, and emerging 2D materials for electronic and photonic devices IX, 99320A. 2016.

[24] Ceretti E, Ginestra PS, Ghazinejad M, Fiorentino A, Madou M. Electrospinning and characterization of polymer-graphene powder scaffolds. CIRP Ann 2017;66(1).

[25] Chen S, Nakamoto T, Kawazoe N. Engineering multi-layered skeletal muscle tissue by using 3D microgrooved collagen scaffolds. Biomaterials 2015;73:23-31.

[26] Ginestra P, Fiorentino A, Ceretti E. Micro-structuring of titanium collectors by laser ablation technique: a novel approach to produce micro-patterned scaffolds for tissue engineering applications. Proc CIRP 2017;65:19-24.

[27] Ginestra P, Pandini S, Fiorentino A, Benzoni P, Dell'Era P, Ceretti E. Microstructured scaffold for cellular guided orientation : PCL electrospinning on laser ablated titanium collector. CIRP J Manuf Sci Technol; 19: 147-157.

[28] Ceretti E, Ginestra P, Neto PI, Fiorentino A, Da Silva JVL. Multi-layered scaffolds production via Fused Deposition Modeling (FDM) using an open source 3D printer: process parameters optimization for dimensional accuracy and design reproducibility. Proc CIRP 2017;65:13-8.

[29] Chang HI, Wang Y. Eberli Daniel, editor. Cell responses to surface and architecture of tissue engineering scaffolds, regenerative medicine and tissue engineering - cells and biomaterials. InTech978-953-307-663-8; 2011.

[30] Loh QL, Choong C. Three-dimensional scaffolds for tissue engineering applications: role of porosity and pore size. Tissue Eng B Rev 2013;19(6):485-502.

[31] Yang K, Kyuhwan J, Eunkyung K, Jin K, Kook IP, Jinseok K, et al. Nanotopographical manipulation of focal adhesion formation for enhanced differentiation of human neural stem cells. Appl Mater Interfaces 2013;5:10529-40.

[32] Gupta D, Venugopal J, Prabhakaran MP, Giri Dev VR, Low S, Choon AT, et al. Aligned and random nanofibrous substrate for the in vitro culture of Schwann cells for neural tissue engineering. Acta Biomater 2009;5:2560-9.

[33] Richardson JA, Rementer CW, Bruder JM, Hoffman-Kim D. Guidance of dorsal root ganglion neurites and Schwann cells by isolated Schwann cell topography on poly (dimethylsiloxane) conduits and films. J Neural Eng 2001:8-12.

[34] Limongi T, Schipani R, Di Vito A, Giugni A, Francardi M, Torre B, et al. Photolithography and micromolding techniques for the realization of 3D polycaprolactone scaffolds for tissue engineering applications. Microelectron Eng 2015;141:135-9.

[35] Tran KTM, Nguyen TD. Lithography-based methods to manufacture biomaterials at small scales. J Sci Adv Mater Dev 2017;2:1-14.

[36] Bajaj P, Schweller RM, Khademhosseini A, West JL, Bashir R. Biofabrication strategies for tissue engineering and regenerative medicine. Annu Rev Biomed Eng 2014;16:247-76.

[37] Fuhrer E, Bäcker A, Kraft S, Gruhl FJ, Kirsch M, MacKinnon N, et al. 3D carbon scaffolds for neural stem cell culture and magnetic resonance imaging. Adv Healthcare Mater 2018;7:1700915.

[38] Zhou H, Gupta A, Zou T, Zhou J. Photoresist derived carbon for growth and differentiation of neuronal cells. Int J Mol Sci 2007;8:884-93.

[39] Tan YC, Fisher JS, Lee AI, Cristini V, Lee AP. Design of microfluidic channel geometries for the control of droplet volume, chemical concentration, and sorting. Lab a Chip 2004;4:292-8.

[40] Green JV, Kniazeva T, Abedi M, Sokhey DS, Taslim M, Murthy SK. Effect of channel geometry on cell adhesion in microfluidic devices. Lab a Chip 2009;9:677-85.

[41] Mobasseri A, Faroni A, Minogue BM, Downes S, Terenghi G, Reid AJ. Polymer scaffolds with preferential parallel grooves enhance nerve regeneration. Tissue Eng Part A 2015;21(5):1152-62.

[42] SU-8 data sheet from. Sep. 2008http://www.microchem.com/products/su_eight. htm.

[43] Martinez-Duarte R. Label-free cell sorting using carbon-electrode dielectrophoresis and centrifugal microfluidics. Irvine, CA, USA: University of California; 2010.

[44] Quang LN, Kurek M, Larsen PE, Schmid S, Boisen A, Keller SS. Fabrication and characterization of pyrolytic carbon string resonators. 42nd international conference on micro and nano engineering, Vienna, Austria. Sept. 2016. p. 19-23.

[45] Singh A, Jayaram J, Madou M, Akbara S. Pyrolysis of negative photoresists to fabricate carbon structures for microelectromechanical systems and electrochemical applications. J Electrochem Soc 2002;149:78-83.

[46] Zhang J, Chan-Park MB, Conner SR. Effect of exposure dose on the replication fidelity and profile of very high aspect ratio microchannels in SU-8. Lab a Chip 2004:4:646-53.

[47] Rasband WS. ImageJ, U. S. Bethesda, Maryland, USA: National Institutes of Health; 1997-2014http://imagej.nih.gov/ij/.

[48] Pérez JMM, Pascau J. Image processing with ImageJ. Packet Publishing9781783283958; 2013.

[49] Ranganathan S, McCreery R, Majji SM, Madou MJ. Photoresist-derived carbon for microelectromechanical systems and electrochemical applications. J Electrochem Soc 2000;147:277-82

[50] http://www.mitakakohki.co.jp.

[51] www.digitalsurf.com.

[52] Lyons AM, Hale LP, Wilkins CW. J Vac Sci Technol A 1985·B 3:447.

[53] Peterman M, Huie P, Bloom D, Fishmann H. J Micromech Microeng 2003;13:380-2.

[54] Benzoni P, Ginestra P, Altomare L, et al. Biomanufacturing of a chitosan/collagen scaffold to drive adhesion and alignment of human cardiomyocyte derived from stem cells. Proc CIRP 2016;49:113-20.

[55] Ginestra PS, Ferraro RM, Lanzi G, Giliani S, Ceretti E. Production of micro-patterned substrates to direct human iPSCs-derived neural stem cells orientation and interaction. Proc CIRP 2017;65:225-30. 